\title{
'CRISTOFOBIA' (PROJETO DE LEI № 1.804/2015): UMA ABORDAGEM SOBRE $O$ LIMITE ENTRE RELIGIÃO E DIREITO NUM ESTADO LAICO
}

\author{
Bruno Nascimento De Couto, Rogério José Da Silva. \\ Universidade do Oeste Paulista - UNOESTE, Curso de Direito, Presidente Prudente, SP. E-mail: \\ bruno.cnasc@gmail.com
}

\section{RESUMO}

O objetivo deste trabalho foi apresentar uma análise crítica referente ao Projeto de Lei no 1.804/2015, em trâmite na Câmara dos Deputados, confrontando-o com o conceito de Estado Laico, bem como interpretando-o conforme os métodos da hermenêutica jurídica. Levanta-se o questionamento a respeito de ainda hoje ser necessária a análise dos limites entre religião e direito. Conclui-se, por fim, data máxima vênia opiniões contrárias que tal projeto não deva ser aprovado, por violar as características laicas estabelecidas na Constituição Federal de 1988.

Palavras-chaves: Estado Laico; Cristianismo; Projeto de Lei no 1.804/2015; Interpretação de leis; Parada do Orgulho LGBT.

\section{CHRISTIANPHOBIA (DRAFT LAW № 1.804/2015): AN APPROACH ON THE BOUNDARY BETWEEN RELIGION AND RIGHT IN SECULAR STATE}

\begin{abstract}
The objective of this study was to present a critical analysis regarding the Draft Law No. $1.804 / 2015$, pending in the House of Representatives, comparing it with the concept of Secular State and interpreting it as the methods of legal interpretation. Arise questioning about still be necessary to analyze the boundaries between religion and law. It follows, finally, maximum data venia contrary opinions that such a project should not be approved, for violating the secular characteristics established in the Federal Constitution of 1988.
\end{abstract}

Keywords: Secular State; Christianity; Draft Law no 1.804/2015; Interpretation of laws; LGBT Pride Parade. 


\section{INTRODUÇÃO}

O presente trabalho objetiva analisar criticamente o Projeto Lei no 1.804/2015, de autoria do Dep. Estadual Sérgio Rosso, questionando essencialmente a necessidade de se propor projeto com agravamento de pena tipificação mais rígida a crime já existente, o que em nosso entender apenas intensifica a crescente rivalidade entre religião e direito. 0 presente projeto propõe alteração na disposição do art. 208 do Código Penal, prevendo pena de 4 (quatro) a 8 (oito) anos e multa, acrescentando no art. 1 을 da Lei $n=8.072 / 1990$, o inciso IX, classificando-o como crime hediondo.

No primeiro capítulo serão estabelecidos alguns parâmetros e conceitos a respeito do Estado Laico, sua origem e evolução, bem como sua previsão constitucional no ordenamento jurídico brasileiro.

Em seguida, aborda-se o tema da previsão à liberdade de religião e de crença: seu conceito e restrições a esse direito.

No terceiro capítulo, direciona-se o estudo para as técnicas de hermenêutica jurídica, listando e conceituando os métodos interpretativos.

No quarto capítulo esboça-se uma análise crítica das razões que levaram à edição de tal projeto, pondo-o em perspectiva de contraste com as previsões de um Estado Laico na Constituição Federal de 1988.

O tema proposto é de interesse para a reflexão crítica no Direito, tendo em vista que se pauta sobre assuntos como a relação entre religião e Estado, bem como a liberdade constitucional de possuir, ou não, uma crença, além de ratificar a necessária laicidade do Estado.

\section{O ESTADO LAICO E A CONSTITUIÇÃO FEDERAL DE 1988}

De três formas pode ocorrer o relacionamento entre Estado e religião: I) união; II) confusão e III) separação (SILVA NETO, 2013, p. 52). Neste último, tem-se o estado laico, que nas palavras de Scalquette (2013, p. 120), é aquele que "deve ser neutro em face da religião, não apoiando uma ou outra religião especificamente".

Historicamente, é possível perceber que o Estado, desde a sua formação, esteve em estreita consonância com a religião predominante em cada época. Suas decisões eram geradas a partir de orientações da doutrina religiosa.

No entanto, com o advento da Revolução Francesa e o movimento lluminista (especialmente entre 1789 e 1799), começa-se a se efetivar um certo distanciamento entre as duas instituições, visto que a máxima do momento era a preferência pela utilização da razão e da ciência para as produções da época em detrimento das crenças religiosas.

No Brasil, desde sua descoberta até a promulgação da Constituição de 1891, houve evidente prevalência da influência da Igreja no meio político-administrativo. Tamanha era seu poder que, conforme se vê na Constituição de 1824, o Catolicismo era tido como a religião oficial do Brasil, como se lê no art. 5o do mesmo texto ${ }^{1}$. Mesmo após as manifestações iluministas e francesas, a ideia de um Estado laico brasileiro só foi concebida após quase quatro séculos de seu descobrimento.

Em 1988 veio a promulgação do atual texto constitucional, que prevê em seu art. 19:

Art. 19. É vedado à União, aos Estados, ao Distrito Federal e aos Municípios:

I - Estabelecer cultos religiosos ou igrejas, subvencioná-los, embaraçar-lhes o funcionamento ou manter com eles ou seus representantes relações de

\footnotetext{
1 “Art. 5. A Religião Catholica Apostolica Romana continuará a ser a Religião do Imperio. Todas as outras Religiões serão permitidas com seu culto domestico, ou particular em casas para isso destinadas, sem fórma alguma exterior do Templo." (Texto original da "CONSTITUIÇÃO POLITICA DO IMPERIO DO BRAZIL" (DE 25 DE MARÇO DE 1824). Ressalte-se que, mesmo em 1824, apesar da religião oficial, havia a explícita outorga à liberdade de crenças, o que se subentende também a liberdade de não crer, bem como analisar criticamente o papel das religiões.
} 
dependência ou aliança, ressalvada, na forma da lei, a colaboração de interesse público.

Dantas (2015) afirma que a Constituição, ao consagrar o direito à inviolabilidade da liberdade de crença e de consciência, tanto em caráter religioso, como filosófico e político, "evidencia o caráter laico do Estado brasileiro, inexistindo uma religião oficial (p. 323)".

Importante assinalar que a afirmação de um Estado Laico não o caracteriza como um Estado ateu, ou um Estado sem religião. Ensina Pontes de Miranda (apud PEREIRA, Vitor Maurício Fiorito) que a "liberdade de crença compreende a liberdade de ter uma crença e a de o ter uma crença". Sendo assim, faz-se importante a previsão do art. 5ㅇ, VI, para a concretização de um Estado Laico.

\section{A LIBERDADE À CRENÇA: CONCEITO E RESTRIÇÕES}

$\mathrm{O}$ art. 5ㅇ, VI estabelece a liberdade de culto e liberdade religiosa. Por liberdade religiosa, entenda-se como aquela que "está presa a uma prerrogativa conferida à pessoa de acreditar na existência de uma divindade e professar a respectiva fé". Assim conceitua Manoel Jorge e Silva Neto (2013), em sua obra Proteção Constitucional à Liberdade Religiosa. Tal liberdade, abrange também "a livre escolha da forma como poderá adorar a divindade: cantando, dançando, meditando, tocando instrumentos", prossegue o autor.

Contudo, como toda garantia fundamental, esta encontra também algumas limitações. Alexandre de Moraes (2013) lista que somente em duas hipóteses alguém pode ser privado do seu direito à religião, as quais são: não cumprimento de uma obrigação a todos imposta e descumprimento de prestação alternativa, fixada em lei. O mesmo autor acrescenta que somente "enquanto não for contrário à ordem, tranquilidade e sossegos públicos, bem como compatível com os bons costumes" (p.48), o direito ao culto é assegurado.

A intenção de nosso legislador constituinte originário, em momento algum, foi a de vedar o culto ou o favorecimento de dado credo, e sim garantir "a não interferência do Estado na religião e, em contrapartida, veda a interferência dela no Estado" (TRINDADE, 2015, p. 95).

\section{A INTERPRETAÇÃO DA LEI E OS MÉTODOS INTERPRETATIVOS E SEUS EFEITOS}

Hans Kelsen, na "Teoria Pura do Direito", definiu interpretação como sendo a "operação mental que acompanha o processo da aplicação do Direito no seu progredir de um escalão superior para um escalão inferior [...]" (KELSEN, p. 256). A relação entre um escalão e outro é de determinação e vinculação, assim a Constituição regula os atos pelos quais são produzidas as leis inferiores. Entretanto, tal determinação jamais pode ser tomada por absoluta. É necessário que haja espaços, brechas, para que se tenha uma apreciação da norma superior, de forma a alcançar seu real sentido. Dessa maneira, Kelsen atribui às normas do escalão superior a característica de um quadro ou moldura, o qual as normas inferiores preenchem.

A partir dessa classificação das normas jurídicas, tem-se que todo ato de edição de leis, é "em parte, determinado pelo Direito e, em parte, indeterminado [...]" (KELSEN, p. 257). A indeterminação pode ser intencionada pelo próprio legislador, ou ser meramente acidental. Quando se fala em indeterminação intencionada, toma-se por exemplo a possibilidade de um juiz em escolher a aplicação de uma pena pecuniária ou uma pena restritiva de liberdade, quando o dispositivo assim prevê. É o caso do próprio art. 208 do Código Penal - em sua redação atual, que trata dos crimes contra o sentimento religioso -, ao prever como pena a aplicação de detenção ou multa. A aplicação de uma ou outra é realizada pelo juiz da demanda ao considerar a especificidade do caso.

Já em relação à indeterminação não-intencionada, ou acidental, funda-se no próprio texto da lei, ao utilizar palavras e expressões que possuem diversos significados e que o operador do 
Direito, na busca pela efetivação deste, buscará o sentido que mais se adequar ao caso concreto que lhe é apresentado.

Elencam-se como técnicas interpretativas: I) a gramatical; II) a lógico-sistemática; III) a histórica; IV) a sociológica e V) a teleológica. Através da técnica gramatical, "o hermeneuta se debruça sobre as expressões normativas, investigando a origem etimológica dos vocábulos e aplicando as regras estruturais de concordância ou regência, verbal e nominal" (SOARES, 2013, p. 31). A técnica lógico-sistemática, pelo mesmo autor, "consiste em referir o texto ao contexto normativo de que faz parte" (p. 32), relacionando a norma ao ordenamento jurídico por completo, incluindo outros. Pela técnica histórica, o interprete analisa não apenas antecedentes imediatos, como declaração de motivos por exemplo, mas também os mediatos, tais como institutos de direito antigo. A seu turno, de acordo Soares (2013, p. 32), a técnica sociológica busca:

conferir a aplicabilidade da norma jurídica às relações sociais que the deram origem; elastecer o sentido da norma a relações novas, inéditas ao momento de sua criação; e temperar o alcance do preceito normativo, a fim de fazê-lo espelhar as necessidades atuais da comunidade jurídica.

Por fim, pelo sistema teleológico, objetiva-se extrair a finalidade, a razão de ser da norma, para então esclarecer seu significado.

Da interpretação, podem-se ter três efeitos. Paulo Nader, em Introdução ao Estudo do Direito, as classifica como: I) interpretação declarativa, da qual o interprete conclui que as palavras externam o sentido exato da norma; II) interpretação restritiva, por meio da qual o hermeneuta subtrai, do texto normativo, palavras e expressões que o legislador não ponderou acerca da sua admissibilidade, e por fim; III) interpretação extensiva, em que o intérprete acrescenta palavras e expressões, que julga necessárias ao entendimento do sentido da norma a qual o legislador falhou ao editar.

\section{O PROJETO DE LEI 1.804/2015 - CRISTOFOBIA}

O referido projeto de lei apresentado à Câmara dos Deputados após a realização da Parada do Orgulho LGBT desse mesmo ano visa a alterar dois dispositivos do ordenamento jurídico brasileiro. São eles o art. 208 do Código Penal e o art. 1ㅇ da Lei no 8.072/1990 (Lei dos Crimes Hediondos), acrescentando em seu rol o inciso "IX- ultraje a culto e impedimento ou perturbação de ato a ele relativo (art. 208)".

Esse projeto foi rapidamente apelidado de 'Cristofobia'. Sua intenção é a de aumentar a pena do art. 208 do Código Penal, hoje apenado com detenção de um mês a um ano, ou multa; para uma pena entre 4 e 8 anos, com aplicação cumulada da pena pecuniária, bem como incluir o mesmo art. no rol dos crimes hediondos, tornando insuscetível de graça ou anistia e ser inafiançável, por força da lei 8.072. Com todo o respeito ao direito de crença dos cidadãos, mas não é de se estranhar o apelido tão rapidamente associado a tal projeto, pois é evidente a gana de calar os descrentes ou críticos aos crentes que ignoram crenças diversas, ou bem mesmo os descrentes.

Em sua justificativa, o parlamentar Rosso (2015, p. 2) afirma que:

A intenção desse projeto de lei é proteger a crença e objetos de culto religiosos dos cidadãos brasileiros, pois o que vem ocorrendo nos últimos anos em manifestações, principalmente LGBTS, é o que podemos chamar de "Cristofobia", com a prática de atos obscenos e degradantes que externam preconceito contra os católicos e evangélicos.

Apresentado à Comissão de Constitucionalidade e Justiça em agosto do mesmo ano, foi (o projeto) aprovado para prosseguir em sua votação. 
Contudo, não podemos nos furtar de observar no projeto uma posição legislativa declinada ao credo cristão. É o que se faz saber através do voto do deputado relator do projeto, na CCJ: "Não podemos tolerar que participantes de manifestações públicas continuem a desrespeitar a fé cristã e os símbolos do cristianismo sem sofrer qualquer punição".

Explicita-se que a preocupação maior do legislador é a proteção de sua crença, o que pode ser entendido como uma postura que deixa de lado outras crenças presentes em nosso país ou até mesmo o absurdo de se considerar que protestos pacíficos contra atos de demonstração de fé (celebrações, cultos, passeatas, etc) sejam atos graves a ponto de se destinar a seus autores penas de até 8 anos de reclusão.

Desde nossa colonização o Brasil vivenciou e absorveu várias religiões e culturas externas. Este é um traço marcante de nosso país, a pluralidade de credos que influenciaram na formação sociocultural do país.

Admitir que um projeto de lei vise à proteção de apenas um credo é ignorar a diversidade de crenças no país e esmagar o princípio da igualdade, estabelecido pelo texto constitucional em seu art. 5으, caput.

É também ignorar o direito à livre manifestação do pensamento daqueles que discordam e que encontram não raros motivos para questionar a prática de imposição de dogmas religiosos que se imiscuem no senso comum como liberdade de pensamento daqueles que não aceitam o pensamento divergente, como por exemplo a tentativa de impor um conceito do que seja "família" (já aprovada em comissão especial de análise do projeto), que contraria a tendência vanguardista jurisprudencial do país, ou o questionamento às isenções fiscais a todos os templos e atividades afins de todas as religiões, ou ainda os e benefícios obscuramente negociados na concessão de emissoras de rádio e TV a alguns setores religiosos em detrimento de outros. A fobia, em verdade, se dá pela impossibilidade de manifestação contrária a um status "sagrado", acima do bem e do mal.

\section{CONCLUSÃO}

Em tão poucas páginas disponíveis para análise e crítica, nossas conclusões só poderiam se limitar a, utilizando-se da hermenêutica jurídica, apontar que o projeto de lei elaborado por um representante da comunidade cristã, mas também representante parlamentar do país, visa ao favorecimento e à proteção de um único credo, ignorando norma prevista constitucionalmente, que veda qualquer tipo de favorecimento a uma determinada religião. Também ignora princípios constitucionais como o da igualdade, da liberdade de crença e o da liberdade de expressão, em especial quando a expressão é das reconhecidas minorias em nosso país, como a comunidade LGBT.

Não há indícios que justifiquem uma preocupação tamanha para justificar um projeto de lei como tal, que não a crítica de minorias não aceitas pelas religiões mais tradicionais. Qualificar a conduta da manifestação crítica a dogmas religiosos como práticas hediondas é uma atitude exasperada e prepotente.

A conversão em lei de tal projeto, sem dúvida, seria reveladora de aumento exponencial da população carcerária, visto que a pena de multa não seria mais aplicada alternativamente, além de tornar o suposto agente inapto para se beneficiar da suspensão condicional da pena, prevista no art. 77 do Código Penal, bem como de seu livramento condicional, previsto no art. 83 do mesmo diploma, já que, para ser beneficiário, a pena não pode ultrapassar dois anos, e a pena mínima prevista no projeto é de quatro anos.

Devem-se atentar todos, nossos parlamentares e a população disposta a colaborar com o pensamento crítico no Direito para que projetos como este não ultrapassem os limites da necessária separação entre o que cabe à religião e o que cabe ao Estado na elaboração das 
normas de Direito. Devemos reforçar, como população que pensa sobre o Direito, a não aceitação de extremismos de toda sorte.

\section{REFERÊNCIAS}

BRASIL. Código Penal. Decreto Lei no. 2.848, de 7 de dezembro de 1940, acessado em 13 de julho de 2016. Disponível em: http://www.planalto.gov.br/ccivil 03/decreto-lei/Del2848compilado.htm BRASIL. Comissão de Constituição, Justiça e Cidadania. Relato: Jefferson Campos, 05 de agosto de 2015. Relatório, acessado em 13 de julho de 2016. Disponível em: http://www.camara.gov.br/proposicoesWeb/prop mostrarintegra?codteor $=1367422 \&$ filename $=P$ $\underline{\mathrm{RL}+1+\mathrm{CCJC}+\% 3 \mathrm{D} \% 3 \mathrm{E}+\mathrm{PL}+1804 / 2015}$

BRASIL. Constituição (1824). Constituição Política do Império do Brazil, acessado em 29 de julho de 2016. Disponível em: http://www.planalto.gov.br/ccivil 03/Constituicao/Constituicao24.htm BRASIL. Constituição (1988). Constituição da República Federativa do Brasil. Brasília: Senado, 1988.

BRASIL. Projeto Lei no 1.804, 08 de junho de 2015. Brasília. Câmara dos Deputados, acessado em 13 de julho de 2016.2 Disponível em: http://www.camara.gov.br/proposicoesWeb/prop mostrarintegra?codteor $=1345072 \&$ filename $=P$

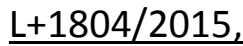

DANTAS, Paulo Roberto de Figueiredo. Curso de Direito Constitucional. 4ạ ed. São Paulo: Atlas. 2015

KELSEN, Hans. Teoria Pura do Direito, acessado em 13 de julho de 2016. Disponível em: http://portalconservador.com/livros/Hans-Kelsen-Teoria-Pura-do-Direito.pdf

MELO, Daniela Mendonça de. A interpretação jurídica de Kelsen, acessado em 13 de julho de 2016. Disponível em: http://www.ambitojuridico.com.br/site/index.php?n link=revista artigos leitura\&artigo id=6957 MORAES, Alexandre de. Direto constitucional. 29a ed. São Paulo: Atlas S.A. 2013

NADER, Paulo. Introdução ao estudo do Direito. 35a ed. Rio de Janeiro: Forense. 2015, acessado em 01 de setembro de 2016. Disponível em: https://integrada.minhabiblioteca.com.br/\#/books/978-85-309-5995-1/cfi/6/72!/4/100/8/2@0:0 PEREIRA, Bruna Caroline. A separação do estado e da igreja para o bem do direito: uma análise jurídica fundamentada no contexto histórico, acessado em 13 de julho de 2016. Disponível em: http://www.ambitojuridico.com.br/site/?n link=revista artigos leitura\&artigo id=4526\&revista caderno=9

PEREIRA. Vitor Maurício Fiorito. O Estado Laico e a Democracia, acessado em 29 de julho de 2016. Disponível em: http://www.amperj.org.br/artigos/view.asp?ID=99-

SCALQUETTE, Rodrigo Arnoni. Histórias do Direito: perspectivas histórico-constitucionais da relação entre Estado e religião. São Paulo: Atlas. 2013.

SILVA NETO, Manoel Jorge. A proteção constitucional à liberdade de crença. $2^{a}$ ed. Salvador/BA: Saraiva. 2013 
SOARES, Ricardo Maurício Freire. Coleção saberes do direito: vol. 60 - Hermenêutica jurídica. 1ạ ed. São Paulo: Saraiva. 2013

TRINDADE, André. Manual de Direito Constitucional. 2ª ed. São Paulo: Saraiva. 2015 